\title{
Komparasi Tujuh Algoritma Identifikasi Fraud ATM Pada PT. Bank Central Asia Tbk
}

\author{
Haliem Sunata*1 ${ }^{1}$, Firman Jodi Azrullah ${ }^{2}$, Yan Rianto ${ }^{3}$ \\ ${ }^{1,2,3}$ Program Studi Magister Ilmu Komputer, Fakultas Teknologi Informasi, Universitas Budi \\ Luhur; Jl. Raya Ciledug, Petukangan Utara, Kebayoran Lama, Jakarta Selatan 12260 \\ , Telp. (021) 5853753, Fax. (021) 5869225 \\ e-mail: *11 haliem.sunata.hs@gmail.com, ${ }^{2}$ azrullahid@gmail.com, ${ }^{3}$ yanr001@ gmail.com
}

\begin{abstract}
Abstrak
Tingginya penggunaan mesin ATM, sehingga menimbulkan celah fraud yang dapat dilakukan oleh pihak ketiga dalam membantu PT. Bank Central Asia Tbk untuk menjaga mesin ATM agar selalu siap digunakan oleh nasabah. Lambat dan sulitnya mengidentifikasi fraud mesin ATM menjadi salah satu kendala yang dihadapi PT. Bank Central Asia Tbk. Dengan adanya permasalahan tersebut maka peneliti mengumpulkan 5 dataset dan melakukan pre-processing dataset sehingga dapat digunakan untuk pemodelan dan pengujian algoritma, guna menjawab permasalahan yang terjadi. Dilakukan 7 perbandingan algoritma diantaranya decision tree, gradient boosted trees, logistic regression, naive bayes (kernel), naive bayes, random forest dan random tree. Setelah dilakukan pemodelan dan pengujian didapatkan hasil bahwa algoritma gradient boosted trees merupakan algoritma terbaik dengan hasil akurasi sebesar $99.85 \%$ dan nilai AUC sebesar 1, tingginya hasil algoritma ini disebabkan karena kecocokan setiap attribut yang diuji dengan karakter gradient boosted trees dimana algoritma ini menyimpan dan mengevaluasi hasil yang ada. Maka algoritma gradient boosted trees merupakan penyelesaian dari permasalahan yang dihadapi oleh PT. Bank Central Asia Tbk.
\end{abstract}

Kata kunci-Fraud, Decision Tree, Gradient Boosted Trees, Logistic Regression, Nä̈ve Bayes

\begin{abstract}
The high use of ATM machines has created a loophole for fraud that can be carried out by third parties in assisting PT. Bank Central Asia Tbk to keep ATM machines ready to use by customers. Not fast and difficult identification of ATM machine fraud is a problem for PT. Bank Central Asia Tbk. With this problem, the researcher collected 5 datasets and pre-processed the dataset so that it could be used for modeling and algorithm testing, in order to answer the problems that occurred. There were seven comparisons of algorithms including decision trees, gradient boosted trees, logistic regression, naive bayes (kernels), naive bayes, random forest and random tree. After modeling and testing, the results show that the gradient boosted trees algorithm is the best algorithm with an accuracy of $99.85 \%$ and an AUC value of 1 , the high result of this algorithm is due to the compatibility of each attribute tested with the gradient boosted trees character that is driven where this algorithm is save and existing results. So the gradient boosted trees algorithm is the solution to the problems that have arisen by PT. Bank Central Asia Tbk.
\end{abstract}

Keywords - Fraud, Decision Tree, Gradient Boosted Trees, Logistic Regression, Nä̈ve Bayes 


\section{PENDAHULUAN}

$\mathrm{G}$ radient boosted trees adalah teknik machine learning untuk masalah regresi dan klasifikasi, yang menghasilkan model prediksi dalam bentuk sebuah ensemble dari model prediksi yang lemah, biasanya pohon keputusan. Metode gradient boosted trees mengasumsikan sebuah nilai real bernilai y [1].

Beberapa penelitian yang menggunakan gradient boosted trees menyimpulkan bahwa algoritma ini menghasilkan hasil yang baik. Seperti pada penelitian yang berjudul "The Combination of Logistic Regression and Gradient Boost Tree for Email Spam Detection” [2]. Penelitian ini menggunakan 2 algoritma yang dikombinasikan antara logistic regression dan gradient bosst tree yang menghasilkan tingkat akurasi 95.13\%, nilai sensitivity sebesar $95.04 \%$ dan specificity sebesar 95.26\%. Pada penelitian yang berjudul "Horse Race Analysis in Credit Card Fraud-Deep Learning, Logistic Regression, and Gradient Boosted Tree" [3]. Gradient boosted tree menghasilkan tingkat AUC yang tinggi sebesar 0.864. Dan pada penelitian berjudul "Integrasi Gradient Boosted Trees dengan Smote dan Bagging untuk Deteksi Kelulusan Mahasiswa" [4]. Gradient boosted tree digabungkan dengan smote dan bagging yang menghasilkan nilai akurasi sebesar $80.57 \%$ dan nilai AUC sebesar 0.858 .

ATM yang merupakan singkatan dari automated teller machine bisa dikatakan sebagai kebutuhan primer dalam hal transaksi dan penarikan uang pihak ketiga. Pihak ketiga merupakan perusahaan yang bekerjasama dengan PT. Bank Central Asia Tbk dalam hal pemeliharaan dan perbaikan mesin ATM. Sedangkan fraud merupakan tindakan penyimpangan atau pembiaran yang sengaja dilakukan untuk mengelabui, menipu, atau memanipulasi bank, nasabah, atau pihak lain, yang terjadi di lingkungan bank dan/atau menggunakan sarana bank sehingga mengakibatkan bank, nasabah, atau pihak lain menderita kerugian dan/atau pelaku fraud memperoleh keuntungan keuangan baik secara langsung maupun tidak langsung

Berdasarkan laporan tahunan berkelanjutan 2018 PT. Bank Central Asia, Saat ini PT Bank Central Asia memiliki lebih dari 19 juta rekening dan 17.778 Mesin ATM [5]. Seiring dengan pertumbuhan ekonomi yang berbanding lurus dengan kebutuhan layanan nasabah terutama pengguna mesin ATM. Dimana mesin ATM rata-rata dilakukan pengisian sebanyak 12 kali perbulan (permesin), PT. Bank Central Asia Tbk dibantu oleh pihak ketiga untuk melakukan pemeliharaan mesin ATM, saat ini terdapat 7 pihak ketiga yang membantu PT. Bank Central Asia Tbk untuk memelihara mesin ATM. Dengan tingginya transaksi disetiap mesin, tidak jarang pihak ketiga melanggar standart operasional yang telah ditentukan oleh PT. Bank Central Asia Tbk. Pelanggaran standart operasional merupakan penyebab terjadinya celah tindakan fraud yang dapat dilakukan oleh pihak ketiga. Saat ini identifikasi fraud rata-rata baru diketahui setelah lebih dari 2 hari dan membutuhkan waktu tambahan untuk mendapatkan penanggung jawab atas tindakan yang terjadi.

Untuk menjawab permasalahan identifikasi fraud yang terjadi, maka peneliti melakukan tinjauan literatur guna menyelesaikan permasalahan yang ada. Pada tinjauan studi literatur terdapat 7 algoritma yang digunakan dalam menyelesaikan permasalahan terkait, diantaranya decesion tree, gradient boosted trees, logistic regression, naive bayes (kernel), naive bayes, random forest dan random tree. Dengan dilakukannya penelitian ini maka dapat menjadi salah satu referensi dalam menyelesaikan permasalahan fraud khususnya dalam bidang perbankan.

\section{METODE PENELITIAN}

\subsection{Algoritma Pengklasifikasian}

Penelitian ini melakukan komparasi menggunakan beberapa model atau algoritma diantaranya adalah decision tree, gradient boosted trees, logistic regression, naive bayes (kernel), naive bayes, random forest dan random tree. Model atau algoritma yang diajukan

Haliem Sunata, et al., [Komparasi Tujuh Algoritma Identifikasi Fraud ATM pada PT. Bank Central Asia Tbk] 
dalam perbandingan ini diawali dengan pengolahan dataset hingga menghasilkan model dan selanjutnya semua model yang telah dibuat akan diuji dengan data yang sama. Hasil pengujian dari algoritma pengklasifikasian ini akan dilakukan komparasi algoritma yang paling baik dengan kasus atau data identifikasi kasus fraud pada PT. Bank Central Asia Tbk.

\subsubsection{Gradient Boosted Trees}

Gradient Boosted Trees adalah teknik machine learning untuk masalah regresi dan klasifikasi, yang menghasilkan model prediksi dalam bentuk sebuah ensemble dari model prediksi yang lemah, biasanya pohon keputusan. Metode Gradient Boosted Trees mengasumsikan sebuah nilai real bernilai y [1].

\subsubsection{Decision Tree}

Decision Tree adalah sebuh metode klasifikasi yang dibangun untuk mendapatkan sebuah kesimpulan dari sejumlah data. Penarikan kesimpulan dibuat dalam bentuk pohon, dimana nantinya hasil kesimpulan berbentuk hierarki pohon yaitu dari akar, batang dan daun yang merepresentasikan hasil keputusan yang dibuat. Sebuah node keputusan (misalnya, Cuaca) memiliki dua cabang atau lebih (misalnya, cerah, mendung dan hujan). Node daun (misalnya, Play) merupakan klasifikasi atau keputusan. Node keputusan paling atas di pohon adalah yang sesuai dengan prediktor terbaik disebut node akar [6].

\subsubsection{Logistic Regression}

Logistic Regression bertujuan untuk menaksir nilai variabel keluaran/output (kriteria atau dependen, Y) berdasarkan skor variabel eksplanatoris (prediktor atau independen, X). Tidak seperti regresi biasa, variabel kriteria dalam regresi logistik adalah variabel binary, yang memiliki skor dikotomi, 1 (untuk munculnya peristiwa) dan 0 (untuk tidak munculnya peristiwa). Misalnya, variabel kelulusan dalam suatu ujian: lulus/sukses $=1$, tidak lulus/gagal $=$ 0 ; keanggotaan dalam organisasi keagamaan: anggota $=1$, bukan anggota $=0$. Dengan adanya keterbatasan skor ini, model regresi linier tidak dapat digunakan karena persyaratan linieritas tidak dapat dipenuhi [7].

\subsubsection{Nä̈ve Bayes Classifier}

Naive Bayes Classifier (NBC) adalah model algoritma probabilitas sederhana yang didasarkan pada teorema bayes. Hukum bayes yang digabungkan dengan 'naive' mengakibatkan setiap variable memiliki sifat yang independen. Naive Bayes Classifier dapat dilatih dengan efisien dalam supervised learning, proses Naive Bayes Classifier menganalogikan ada atau tidak suatu variabel pada suatu kelas tidak memiliki korelasi dengan ada atau tidak variable lain dikelas yang sama. Nä̈ve Bayes Classifier termasuk algoritma yang tergolong supervised learning, sehingga pada prosesnya dibutuhkan data training untuk melakukan klasifikasi. Alur proses klasifikasi dengan menghitung kemungkinan (probability) data yang masuk pada masing-masing class label. Class label dengan tingkat probability terbesar yang akan dijadikan class label data masukan. Naive Bayes Classifier mengadopsi rumus dari teorema bayes, sehingga kompleksitas komputasi menjadi sederhana. Kelebihan lain dari Naive bayes classifier dapat menangani dataset yang beratribut banyak. Rumus persamaan 1 menunjukan rumus dari Naive bayes classifier.

$$
P(C \mid X)=\frac{P(X \mid C) P(C)}{P(X)}
$$

Keterangan:

$\mathrm{X}$ : Prediksi data masukan

C : Hipotesa data masuk pada suatu kelas label 
$\mathrm{P}(\mathrm{C} \mid \mathrm{X})$ : Probabilitas hipotesa berdasarkan kondisi

$\mathrm{P}(\mathrm{C}) \quad$ : Probabilitas hipotesa

$\mathrm{P}(\mathrm{X} \mid \mathrm{C})$ : Probabilitas atas dasar kondisi pada hipotesa

$\mathrm{P}(\mathrm{X}) \quad$ : Probabilitas dari C

$(\mathrm{X} \mid \mathrm{Ci})(\mathrm{Ci})$ dengan memilih yang terbesar sebagai kelas yang dipilih sebagai hasil prediksi. Kelemahan dari Algoritma NBC adalah ketika menjalankan proses training dengan dataset yang memiliki bobot attribute yang tidak seragam (nonnormal distribution/non gaussian distribution) akan berakibat performansi klasifikasi yang tidak sesuai. Oleh sebab itu dibutuhkan cara untuk menangani masalah ini yaitu dengan penerapan fungsi kernel density. Algoritma ini yang dinamakan dengan Naive bayes classifier kernel density estimation. Rumus persamaan 2 menunjukan rumus kernel density estimation.

$$
f(x ; H)=n^{-1} \sum_{i=0}^{n} K_{H}\left(x-x^{(i)}\right)
$$

Pendekatan Kernel digunakan untuk memindahkan fungsi dot ke hyper space. Fungsi kernel yang ada dirumuskan dengan rumus pada rumus persamaan 3:

$$
K_{H}(x)=|H|^{-\frac{1}{2}} K\left(H^{-1 / 2} x\right)
$$

Fungsi kernel diatas dimana $\mathrm{H}$ adalah $\mathrm{d} \times \mathrm{d}$ bandwidth atau bentuk matrix $(\mathrm{BM}) \mathrm{x}=$ $(\mathrm{x} 1 \ldots \mathrm{xd})$ adalah sebuah bentuk dimensi dari $\mathrm{X} . \mathrm{N}$ adalah estimator dari model learning. Fungsi $\mathrm{f}(: \mathrm{H})$ digunakan untuk menentukan rata-rata kepadatan $\mathrm{n}$ kernel pada setiap observasi. Sehingga Fungsi kernel Density estimation naive Bayes seperti persamaan 4:

$$
P i(x i \mid C=c)=\frac{1}{N c h} \sum_{J=1}^{N c} K(x i, x j|i| c)
$$

Dimana k adalah fungsi kernel Gaussian dengan mean 0 dan variance 1, Nc adalah jumlah input data $\mathrm{X}$ yang diprediksi masuk kelas c, $\mathrm{Xj}|\mathrm{i}| \mathrm{c}$ adalah nilai fitur yang terletak pada posisi i dari $\mathrm{j}$ dengan input $\mathrm{X}=(\mathrm{x} 1, \mathrm{x} 2, \mathrm{x} 3 \ldots \mathrm{xn})$ pada kelas $\mathrm{c}$ dan $\mathrm{h}$ adalah bandwidth atau smoothing parameter. Untuk mengoptimalkan nilai klasifikasi, parameter $\mathrm{h}$ harus dicari nilai optimalnya. Tujuan dari Kernel Density Estimation (KDE) adalah dapat memanipulasi atribut yang bersifat kuantitas, sehingga bobot tiap attribute dapat sesuai [8].

\subsubsection{Random Forrest}

Random Forest adalah sebuah metode bisa yang digunakan untuk klasifikasi, regresi, ataupun tujuan lainnya. Random Forest bekerja dengan cara membangun lebih dari 1 Decision Tree secara random saat training. Hasil yang diberikan oleh Random Forest untuk klasifikasi adalah modus dari decision tree-decision treenya. Sementara nilai yang diberikan untuk regresi adalah mean.

Dengan membuat banyak Decision Tree secara random, maka sebenarnya banyak dari pohon-pohon yang dibuat oleh metode Random Forest menjadi kurang berguna. Namun Random Forest mampu menjadi sebuah metode klasifikasi yang cukup baik, karena beberapa Decision Tree yang ikut dibuat saat konstruksi, ternyata memiliki kemampuan prediksi yang baik. Saat dilakukan pemilihan untuk menentukan klasifikasi secara keseluruhan, pohon-pohon yang buruk akan membuat prediksi yang acak dan saling bertentangan, sehingga jawaban dari beberapa decision tree yang merupakan prediktor yang baik akan muncul sebagai jawaban.

Random Forest pertama kali dipublikasikan secara resmi oleh Leo Breiman pada tahun 2001. Random Forest dikembangkan untuk memperbaiki metode-metode Decision Tree yang

Haliem Sunata, et al., [Komparasi Tujuh Algoritma Identifikasi Fraud ATM pada PT. Bank Central Asia Tbk] 
rawan overfitting. Dalam perkembangannya Random Forest menjadi salah satu metode yang populer di bidang machine learning. Hal ini diakibatkan oleh mudahnya penggunaan Random Forest, yang mampu mencapai akurasi tinggi tanpa perlu melakukan banyak parameter tuning [6].

\subsubsection{Random Tree}

Random Tree merupakan sebuah pohon keputusan. Random Tree menggunakan subset acak atribut untuk setiap perpecahan. Random Tree mempelajari pohon keputusan yakni data nominal dan numerik. Pohon keputusan adalah metode klasifikasi yang kuat yang dapat dengan mudah dipahami [1].

\subsection{Data Selection}

Pemilihan (seleksi) data dari sekumpulan data operasional perlu dilakukan sebelum tahap penggalian informasi dalam Knowledge Discovery in Database (KDD) dimulai. Data hasil seleksi yang akan digunakan untuk proses data mining, disimpan dalam suatu berkas terpisah dari basis data operasional [9].

\subsection{Preprocessing Data / Cleaning}

Sebelum proses data mining dapat dilaksanakan, perlu dilakukan proses cleaning pada data yang menjadi fokus Knowledge Discovery in Database (KDD). Proses cleaning mencakup antara lain membuang duplikasi data, memeriksa data yang inkonsisten, dan memperbaiki kesalahan pada data, seperti kesalahan cetak. Juga dilakukan proses enrichment, yaitu proses "memperkaya" data yang sudah ada dengan data atau informasi lain yang relevan dan diperlukan untuk Knowledge Discovery in Database (KDD), seperti data atau informasi eksternal lainnya yang diperlukan [9].

\subsection{Data Transformation}

Coding adalah proses transformasi pada data yang telah dipilih, sehingga data tersebut sesuai untuk proses data mining. Proses coding dalam Knowledge Discovery in Database (KDD) merupakan proses kreatif dan sangat tergantung pada jenis atau pola informasi yang akan dicari dalam basis data [9].

\subsection{Langkah Penelitian}

Langkah-langkah yang dilakukan dalam penelitian ini secara umum dapat dilihat pada gambar dibawah ini: 


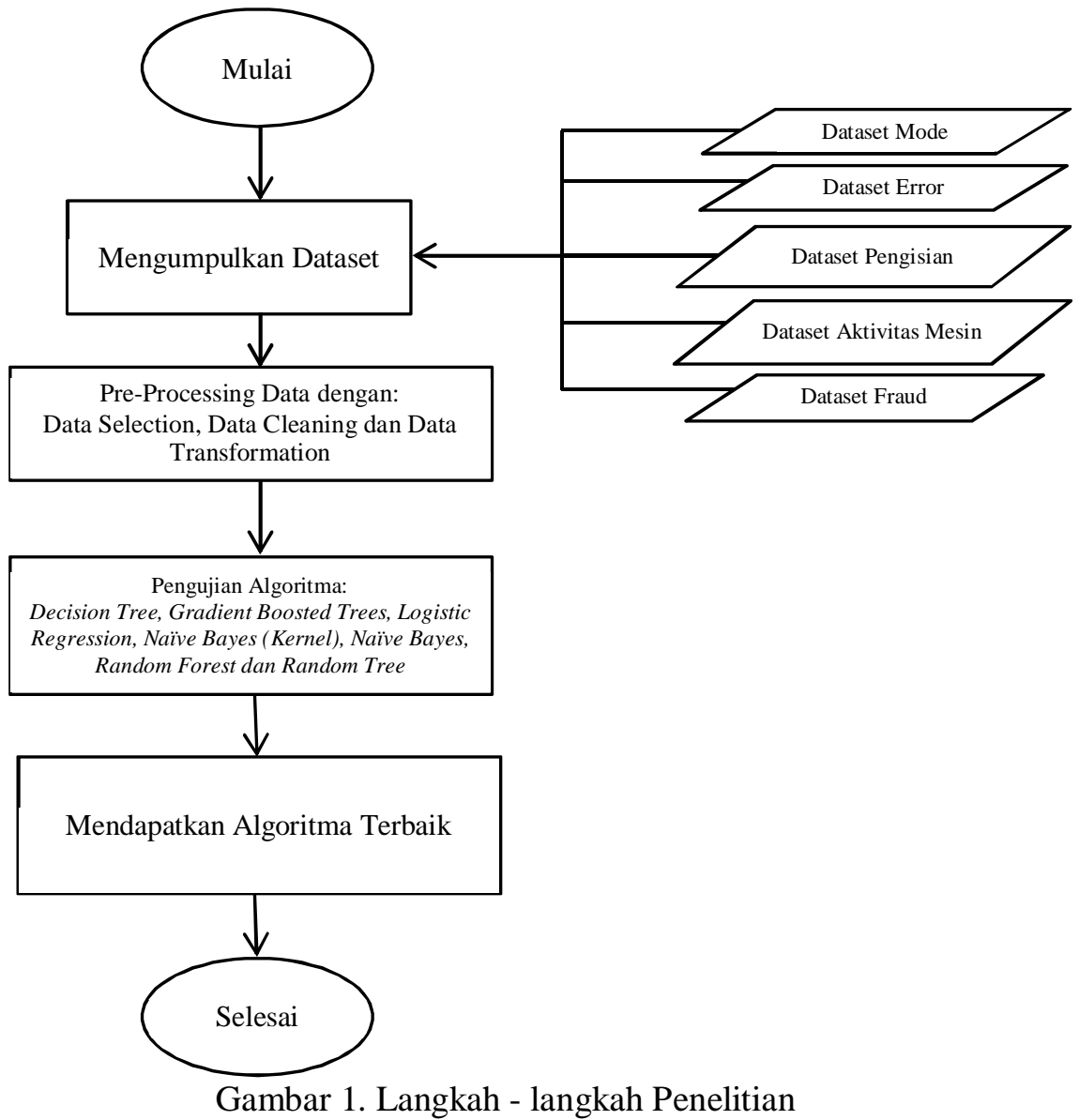

\section{HASIL DAN PEMBAHASAN}

\subsection{Pengumpulan Data}

Pada penelitian ini penulis menggunakan 2 teknik pengumpulan data yaitu penelitian langsung dan studi pustaka. Diantaranya terdiri dari:

a. Penelitian langsung

- Observasi langsung, langsung melihat data kegiatan operational secara langsung. Dari identifikasi kasus fraud, penelusuran fraud hingga proses akhir yaitu punishment terhadap pihak ketiga yang melakukan tindakan fraud

- Wawancara, melakukan interaksi secara langsung maupun tidak langsung dengan tim penelusuran selisih untuk mendapatkan informasi yang sesuai dengan kebutuhan unit kerja, sehingga dapat membuat model yang tepat pada penelitian ini

- Dokumentasi meminta sampel 1 bulan aktivitas mesin ATM diantaranya:

- Dataset mode adalah dataset yang terbagi mejadi 2 yaitu normal mode (tindakan perbaikan mesin yang hanya membuka pintu atas mesin) dan supervisor mode (tindakan perbaikan mesin secara keseluruhan, termasuk membuka brankas mesin ATM).

- Dataset error adalah dataset kerusakan yang dialami oleh mesin atm sebagai notifikasi atau pemberitahuan untuk pihak ketiga dan dipantau oleh tim monitoring BCA, sehingga apabila terdapat notifikasi petugas perbaikan pihak ketiga segera melakukan perbaikan sesuai dengan notifikasi yang diberikan oleh mesin ATM. 
- Dataset pengisian adalah dataset yang berisi penjadwalan pengisian uang pada mesin ATM yang dilakukan oleh pihak ketiga dan dijadwalkan oleh analis pengisian BCA secara periodic

- Dataset aktivitas mesin adalah dataset yang berisi pencatatan secara otomatis oleh mesin ATM terhadap kegiatan pihak ketiga yang melakukan tindakan pengisian/perbaikan yang dilakukan oleh pihak ketiga terhadap mesin ATM dan dikirimkan melalui jaringan virtual dan diinformasikan ke tim monitoring BCA.

- Dataset Fraud adalah dataset yang berisi keterangan mesin, tanggal fraud dan keterangan terjadi fraud atau tindakan yang normal.

b. Studi Pustaka

Referensi yang digunakan oleh penulis sebagai acuan yang relevan dalam membuat serta mempelajari dalam membuat penyelesaian permasalahan terhadap penelitian yang dibuat. Diantaranya terdapat 10 studi pustaka yang menjadi acuan bagi penulis [10].

\subsection{Data Pre-Processing}

Dilakukan pre-processing dengan aplikasi Rstudio dan pada data pre-processing ini menggunakan 5 dataset.

\subsection{Pengujian Menggunakan Rapid Miner}

Pengujian model algoritma dengan rapidminer pada penelitian ini, untuk mencari tingkat akurasi tertinggi dan nilai AUC yang tertinggi sehingga didapatkan algoritma yang paling tepat dalam menyelesaikan permasalahan identifikasi kasus fraud mesin ATM pada PT. Bank Central Asia Tbk. Pada tahap ini, peneliti menguji 7 algoritma untuk menyelesaikan permasalahan ini diantaranya Gradient Boosted Trees, Decesion Tree, Random Forest, Logistic Regression, Nä̈ve Bayes (Kernel), Random Tree dan Nä̈ve Bayes.

\subsection{Tabel Perbandingan}

Berdasarkan hasil pengujian maka didapatkan hasil sebagai berikut:

Tabel 1. Hasil Perbandingan

\begin{tabular}{|l|c|c|}
\hline \multicolumn{1}{|c|}{ Algoritma } & Akurasi & AUC \\
\hline Decesion Tree & $83.64 \%$ & 0.931 \\
\hline $\begin{array}{l}\text { Gradient Boosted } \\
\text { Trees }\end{array}$ & $99.85 \%$ & 1 \\
\hline $\begin{array}{l}\text { Logistic } \\
\text { Regression }\end{array}$ & $82.10 \%$ & 0.842 \\
\hline $\begin{array}{l}\text { Naïve Bayes ( } \\
\text { Kernel ) }\end{array}$ & $74.57 \%$ & 0.826 \\
\hline Naive Bayes & $53.01 \%$ & 0.846 \\
\hline Random Forest & $83.55 \%$ & 0.892 \\
\hline Random Tree & $63.05 \%$ & 0.979 \\
\hline
\end{tabular}

Berdasarkan tabel perbandingan 1 Perbandingan Performance algoritma di atas dapat kita simpulkan bahwa algoritma gradient boosted trees merupakan algoritma terbaik dalam menyelesaikan permasalahan ini, hal ini disebabkan karena pada tahap preprocessing data seluruh isi data sudah menjadi terstruktur dengan mentransformasikan nilai menjadi 1 apabila terdapat kegiatan pada mesin ATM dan 0 apabila tidak terdapat kegiatan pada mesin ATM. Dengan data yang terstruktur menjadi 1 dan 0, algoritma gradient boosted trees dapat mengolah data dengan optimal sehingga menghasilkan nilai akurasi dan nilai AUC yang tinggi. 


\subsection{Hasil}

Berdasarkan tabel perbandingan yang terangkum pada tabel 1 perbandingan performance algoritma. Performance keakurasian berdasarkan AUC maka diperoleh hasil sebagi berikut algoritma Gradient Boosted Trees dengan nilai AUC 1, algoritma Random Tree dengan nilai AUC 0.979, algoritma Decesion Tree dengan nilai AUC 0.931, algoritma Random Forest dengan nilai 0.892, algoritma Nä̈ve Bayes dengan nilai 0.846, algoritma Logistic Regression dengan nilai 0.842, algoritma Nä̈ve Bayes ( Kernel ) dengan nilai 0.826.

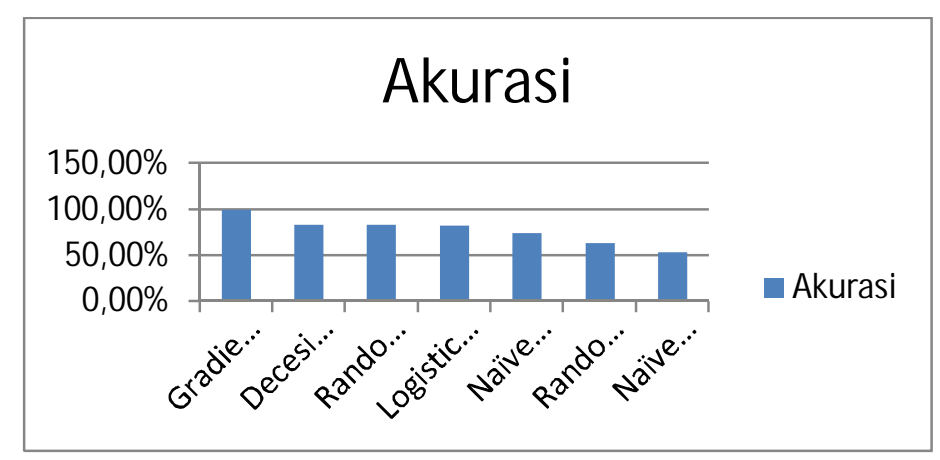

Gambar 2. Grafik Hasil Perbandingan

Pada gambar 2 grafik hasil perbandingan menunjukkan nilai akurasi untuk algoritma Gradient Boosted Trees merupakan algoritma yang terbaik diantara 6 algoritma lainnya, dengan mendapatkan nilai akurasi sebesar $99.85 \%$, algoritma yang kedua yaitu Decesion Tree dengan nilai akurasi sebesar $83.64 \%$, algoritma yang ketiga yaitu Random Forest dengan nilai akurasi sebesar $83.55 \%$, algoritma yang keempat yaitu Logistic Regression dengan nilai akurasi sebesar $82.1 \%$, algoritma yang kelima yaitu Nä̈ve Bayes (Kernel) dengan nilai akurasi sebesar $74.57 \%$, algoritma yang keenam yaitu Random Tree dengan nilai akurasi sebesar $63.05 \%$ dan algoritma yang terakhir adalah Naïve Bayes dengan nilai akurasi sebesar 53.01\%.

Maka diperoleh hasil algoritma Gradient Boosted Trees merupakan algoritma yang terbaik untuk menyelesaikan permasalahan identifikasi fraud pada penelitian ini.

\section{KESIMPULAN}

Berdasarkan permasalahan dan tujuan dari penelitian serta dihubungkan dengan hasil analisis dan pembahasannya, secara garis besar dibuat kesimpulan-kesimpulan diantaranya adalah terdapat permasalahan dalam penanganan fraud mesin ATM yaitu lambat dan sulitnya mendapatkan informasi terkait fraud mesin ATM, terdapat 5 dataset yang digunakan dalam penelitian ini yaitu dataset mode, dataset error, dataset pengisian, dataset aktivitas mesin dan dataset fraud, dilakukan pre-processing dataset sehingga dapat dilakukan pemodelan dan pengujian dengan 7 algoritma (algoritma decession tree, gradient boosted trees, logistic regression, naïve bayes (kernel), random tree dan random forest) dan didapatkan hasil algoritma gradient boosted trees merupakan algoritma terbaik dengan nilai akurasi sebesar 99.85\% dan nilai AUC sebesar 1.

\section{SARAN}

Sehubungan dengan kesimpulan-kesimpulan tersebut, maka saran-saran yang dapat dikemukakan dalam penelitian ini sebagai berikut: 
1. Dari segi praktis, untuk menjawab permasalahan identifikasi kasus fraud mesin ATM maka pengimplementasian algoritma gradient boosted trees menjadi salah satu pilihan yang dapat diimplementasikan. Serta guna mengoptimalkan meningkatkan identifikasi kasus fraud mesin ATM, hendaknya tim monitoring terus mengevaluasi hasil identifikasi kasus fraud sehingga mendapatkan data yang lebih variatif dan menjadi lebih optimal dalam mengidentifikasi fraud mesin ATM.

2. Dari segi teknis, untuk terus mendapatkan hasil yang optimal maka perbandingan dengan pengujian algoritma lain yang berkelanjutan harus terus dilakukan, hal ini disebabkan pola dan data terus bertambah dan berubah.

\section{UCAPAN TERIMA KASIH}

Penulis mengucapkan terima kasih kepada pihak yang telah memberi dukungan secara langsung maupun tidak langsung terhadap penelitian ini.

\section{DAFTAR PUSTAKA}

[1] M. W. Pertiwi, M. F. Adiwisastra, and D. Supriadi, 2019, "Analisa Komparasi Menggunakan 5 Metode Data Mining Dalam Klasifikasi Persentase Wanita Sudah menikah di Usia 15-49 yang Memakai Alat KB (Keluarga Berencana)," J. Khatulistiwa Inform., Vol. 7, No. 1, pp. 37-42, doi: 10.31294/jki.v7i1.5741.

[2] A. Anggraina, R. Primartha, and A. Wijaya, 2019, "The Combination of Logistic Regression And Gradient Boost Tree For Email Spam Detection," J. Phys. Conf. Ser., Vol. 1196, No. 1, doi: 10.1088/1742-6596/1196/1/012013.

[3] G. Rushin, C. Stancil, M. Sun, S. Adams, and P. Beling, 2017, "Horse Race Analysis in Credit Card Fraud - Deep Learning, Logistic Regression, and Gradient Boosted Tree," in 2017 Systems and Information Engineering Design Symposium, SIEDS 2017, doi: 10.1109/SIEDS.2017.7937700.

[4] A. Bisri and R. Rachmatika, 2019, "Integrasi Gradient Boosted Trees Dengan SMOTE dan Bagging Untuk Deteksi Kelulusan Mahasiswa," Vol. 8, No. 4.

[5] PT Bank Central Asia Tbk, 2019., "Laporan Tahunan BCA 2018 Keberlanjutan.”

[6] D. P. Lingga, Chastine Fatichah, 2017, "Deteksi Gempa Berdasarkan Data Twitter Menggunakan Decision Tree, Random Forest, dan SVM," J. Tek. ITS Vol. 6, No. 1, ISSN 2337-3539, Vol. 6, No. 1, p. (2301-9271), doi: 10.1109/ICBBE.2009.5162818.

[7] I. Hadjar, 2017, “Jurnal Phenomenon,” Phenomenon, Vol. 07, No. 1, pp. 187-195

[8] T. B. Sasongko and O. Arifin, 2019, "Implementasi Metode Forward Selection pada Algoritma Support Vector Machine (Svm) dan Naive Bayes Classifier Kernel Density (Studi Kasus Klasifikasi Jalur Minat SMA) Implementation Forward Selection Methods for Support Vector Machine (Svm) and Nä̈ve," Vol. 6, No. 4, pp. 383-388, doi: 10.25126/jtiik.201961000. 
[9] Y. Mardi, 2017, "Data Mining: Klasifikasi Menggunakan Algoritma C4.5," J. Edik Inform., Vol. 2, No. 2, pp. 213-219.

[10] F. A. Huda, 2017, "Pengertian dan Definisi Kajian Pustaka," http://fatkhan.web.id/, [Online]. Available: http://fatkhan.web.id/pengertian-dan-definisi-kajian-pustaka. [Accessed: 09-Sep-2020]. 